American J. of Engineering and Applied Sciences 2 (4): 775-780, 2009

ISSN 1941-7020

(C) 2009 Science Publications

\title{
Restrained Shrinkage-Induced Cracking of Light Weight High Performance Fiber Reinforced Cementitious Composites
}

\author{
${ }^{1}$ Shaikh Faiz Uddin Ahmed and ${ }^{2}$ Hirozo Mihashi \\ ${ }^{1}$ Department of Civil Engineering, Curtin University of Technology, Perth, WA., Australia \\ ${ }^{2}$ Department of Architecture and Building Science, Graduate School of Engineering, \\ Tohoku University, Aoba 06, Aoba-Ku, Sendai 980-8579, Japan
}

\begin{abstract}
Problem statement: Shrinkage induced cracking cause damage to reinforced concrete structures. An experimental study was conducted on restrained shrinkage test of cement mortar and light weight High Performance Fiber Reinforced Cementitious Composites (HPFRCC). Approach: Two types of light weight HPFRCC and a premix mortar containing small amount of fiber were included in the experiment. Results: Results showed the multiple cracks, as many as 49, in light weight HPFRCC specimens compared to few cracks (about six cracks) in the premix mortar specimen. At the end of shrinkage test, the width of the cracks in the mortar specimen was more than $250 \mu \mathrm{m}$ with the largest crack width of about $400 \mu \mathrm{m}$. However, the scenario was quite different in light weight HPFRCC specimens, where the width of almost all cracks was less than $100 \mu \mathrm{m}$. Conclusion: The higher number of multiple cracks with small cracks width in light weight HPFRCC specimens due to drying shrinkage was due to their strain hardening and ductile behavior compared to quasi brittle behavior of premix mortar where less number of wide cracks was observed.
\end{abstract}

Key words: Shrinkage, high performance fiber reinforced cementitious composites, Cement mortar.

\section{INTRODUCTION}

Shrinkage is unavoidable in concrete. The amount of shrinkage depends on many factors including the cement content, aggregate properties, the mixture composition, temperature and the relative humidity of the environment, the age of the concrete and the size of the structure. If concrete is restrained from shrinking, tensile stresses develop and once the tensile stresses exceed the tensile strength of concrete, the concrete cracks. One way to reduce the crack opening is to reinforce the concrete with short randomly distributed fibers.

Ring test is commonly used to assess the potential for restrained shrinkage induced cracking due to its simplicity and versatility. In the ring test the concrete is cast around the hollow steel cylinder. As the concrete dries, shrinkage is prevented by the steel ring, thus resulting in the development of tensile stresses in the concrete. The ring specimen geometry is frequently preferred because of the difficulties associated with providing adequate end restraint in other methods. The simple geometry allows the specimen to be fabricated easily and the low cost of the system enables several tests to be conducted concurrently over a long period of time.
Several projects have investigated the restrained shrinkage induced cracking of ordinary concrete ${ }^{[1-3]}$ and fiber reinforced concrete ${ }^{[4-7]}$. Grzybowski and Shah ${ }^{[4]}$ investigated the shrinkage cracking of fiber reinforced concrete using a ring-type specimen to simulate restrained shrinkage cracking. Two types of fibers (steel and polypropylene) with the amount of fibers ranged from $0.1-1.5 \%$ by volume were used. The results indicated that the addition of small amount of steel fibers $(0.25 \%$ by volume) reduced the average crack widths by about $20 \%$ and the maximum crack width by about 50\% in comparison with plain concrete. Polypropylene fibers showed much less effective in reducing crack widths than steel fibers. However, the maximum number of cracks was limited around 2 or 3 . Voigt et al. ${ }^{[6]}$ also used different types of steel and polypropylene fibers in fiber reinforced concrete and reported that steel fiber is the best performing reinforcement concerning maximum crack width compared to its counterpart polypropylene fiber. Multiple cracks were not observed in those composites. High Performance Fiber Reinforced Cementitious Composites (HPFRCC) that exhibit strain hardening and multiple cracking behavior in uni-axial tension have also been used to evaluate their performance

Corresponding Author: Shaikh Faiz Uddin Ahmed, Department of Civil Engineering, Curtin University of Technology, Perth, WA., Australia 
Am. J. Engg. \& Applied Sci., 2 (4): 775-780, 2009

against restrained shrinkage induced cracking by ${ }^{[8,9]}$. Weimann and $\mathrm{Li}^{[8]}$ reported multiple cracks (as many as 10) of much smaller width (as small as $0.03 \mathrm{~mm}$ ) in ring specimens made with Engineered Cementitious Composites (ECC) containing 2\% PVA (polyvinyl alcohol) fiber by volume. Multiple cracks with small crack width are also reported by Wittmann et al. ${ }^{[9]}$ in PVA fiber reinforced HPFRCC specimen in the ring test.

While little studies are evaluated the restrained shrinkage induced cracking of HPFRCC, however, no study is reported on the light weight HPFRCC. This study presents the results on the restrained shrinkage induced cracking of light weight HPFRCC due to drying. Comparison is also made with premix mortar.

\section{MATERIALS AND METHODS}

Materials and mix proportions: Two types of light weight HPFRCCs and two types of mortar are considered in this study. The matrixes for the light weight HPFRCCs in this study are consisted of ordinary Portland cement and two types of light weight sands in $14 \%$ by volume. Both light weight HPFRCCs are reinforced with two different types of PVA fibers in different volume fractions containing 2\% PVA fiber of $12 \mathrm{~mm}$ in length and $100 \mu \mathrm{m}$ in diameter and 1\% PVA fiber of $6 \mathrm{~mm}$ in length and $40 \mu \mathrm{m}$ in diameter. The first composite contained light weight sand type FL1 while the second contained type FL0. The light weight sand type FL0 is finer but heavier than FL1 (Table 1). Both light weight composites exhibited strain hardening and multiple cracking behaviors in bending, while the premix mortars did not exhibit strain hardening behavior (Fig. 1). The light weight HPFRCCs are about 22-38\% lighter than the mortar ${ }^{[10]}$. The properties of light weight sands are given in Table 1, while the properties of Polyvinyl Alcohol (PVA) fibers are shown in Table 2. Table 3 shows the mix proportions for light weight HPFRCCs and premix mortar. Series 1 and 2 are for light weight hybrid composites containing light weight sand type FL0 and FL1, respectively, while series 3 in Table 4 is the mix proportions for premix cement mortars.

For each series, two cylindrical specimens and two ring specimens were cast. The cylindrical specimens were used to measure the free shrinkage while the ring specimens were used for the restrained shrinkage test. All cylindrical specimens were demolded after $24 \mathrm{~h}$ of casting and wet cured for approximately 7 days. The top surface of the ring specimens were covered with wet burlap for one day after casting. On the second day, the top surface of the ring specimens was sealed with silicon resin. After 3 days the outer PVC ring was removed. A schematic of the ring test setup is shown in Fig. 2.
Table 1: Properties of light weight sand

\begin{tabular}{llll}
\hline Type & $\begin{array}{l}\text { Size of sand } \\
\text { grain }(\mathrm{mm})\end{array}$ & $\begin{array}{l}\text { Unit weight } \\
\left(\mathrm{gm} \mathrm{cm}^{-3}\right)\end{array}$ & $\begin{array}{l}\text { Surface area } \\
\left(\mathrm{cm}^{2} \mathrm{gm}^{-1}\right)\end{array}$ \\
\hline FL0 & 0.6 & 0.675 & 24.7 \\
FL1 & $0.6-1.2$ & 0.220 & $75.8-37.9(50.5$ avg. $)$ \\
\hline
\end{tabular}

Table 2: Properties of PVA fibers

\begin{tabular}{lcllll}
\multicolumn{6}{l}{ Table 2: Properties of PVA fibers } \\
\hline Types & $\begin{array}{l}\text { Length } \\
(\mathrm{mm})\end{array}$ & $\begin{array}{l}\text { Diameter } \\
(\mathrm{mm})\end{array}$ & $\begin{array}{l}\text { Modulus of } \\
\text { elasticity (GPa) }\end{array}$ & $\begin{array}{l}\text { Fiber strength } \\
(\mathrm{MPa})\end{array}$ & $\begin{array}{l}\text { Elongation } \\
(\%)\end{array}$ \\
\hline Thinner & 6 & 0.04 & 40 & 1600 & 6 \\
Thicker & 12 & 0.10 & 25 & 1100 & 10 \\
\hline
\end{tabular}

Table 3: Mix proportion of light weight HPFRCC materials

\begin{tabular}{lllllll}
\hline & $\begin{array}{l}\text { Light } \\
\text { weight }\end{array}$ & \multicolumn{2}{c}{ Mix proportion by wt. (\%) } \\
& sand & & & Viscous & Thicker & Thinner \\
Series & type & Cement & Sand & powder & PVA fiber & PVA fiber \\
\hline 1 & FL0 & 86.5 & 8.9 & 0.8 & 2.5 & 1.3 \\
2 & FL1 & 92.1 & 3.1 & 0.8 & 2.7 & 1.3 \\
\hline
\end{tabular}

Note: Water/cement ratio in both series was 0.62 by weight

Table 4: Mix proportion of cement mortars Mix proportion by wt. (\%)

\begin{tabular}{|c|c|c|c|c|c|}
\hline eric & Cem & $\begin{array}{l}\text { Other cementitious } \\
\text { materials }\end{array}$ & Sands & Fiber & $\begin{array}{l}\text { Viscous } \\
\text { powder }\end{array}$ \\
\hline 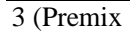 & 48 & 26.3 & 25.4 & $0.2^{*}$ & 0.1 \\
\hline
\end{tabular}
mortar)

Note: Water/cement ratio was 0.54 by weight; *: Length: $6 \mathrm{~mm}$ and diameter: $20 \mu \mathrm{m}$

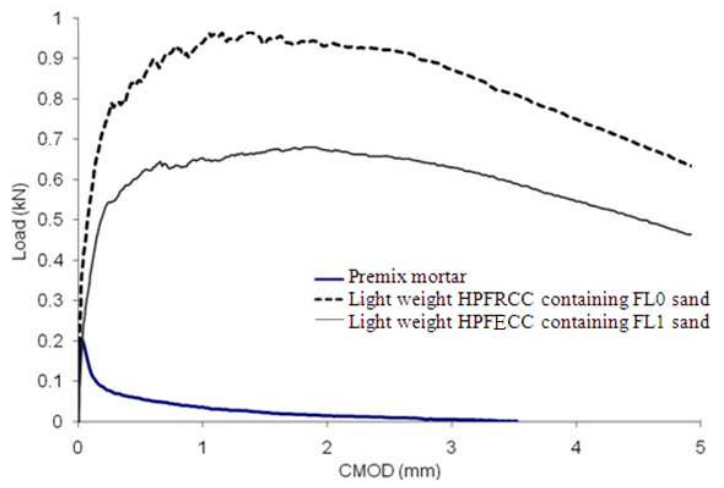

Fig. 1: Strain hardening behavior of light weight HPFRCCs and Premix mortar

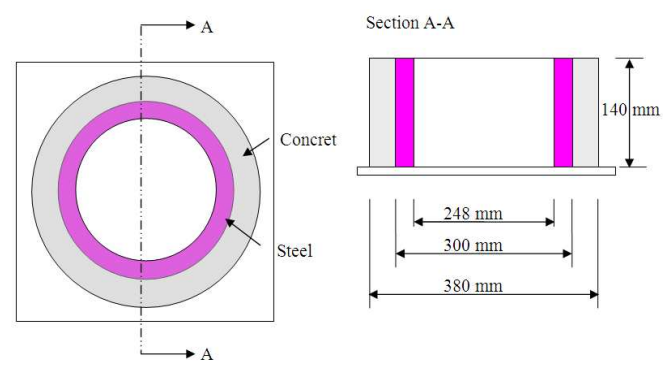

Fig. 2: Dimension of ring specimen used in restrained shrinkage test (not to scale) 
Free shrinkage test: Free shrinkage of cement mortars and the light weight hybrid composites was measured on cylinders with a length of $100 \mathrm{~mm}$ and a diameter of $50 \mathrm{~mm}$. A gauge was placed at the center of all cylindrical specimens in order to measure the free shrinkage automatically (Fig. 3). All cylindrical specimens were placed into the laboratory atmosphere with $\mathrm{RH}=60 \%$ at $20^{\circ} \mathrm{C}$. A typical experimental setup is shown in Fig. 4.

Restrained shrinkage test: Metallic rings are the most widely used devices to test the restrain shrinkage of concrete. A mortar ring is cast around a steel ring. Because steel is stiffer than cement mortar, volume change of mortar is prevented to a certain extent, which depends on the ring's dimensions and properties of mix. In this study, the depth of the mortar and steel rings is considered as $140 \mathrm{~mm}$ (Fig. 2). The inner radius of the steel ring is $125 \mathrm{~mm}$, while the outer radius of steel ring and the inner radius of the mortar ring is $150 \mathrm{~mm}$.

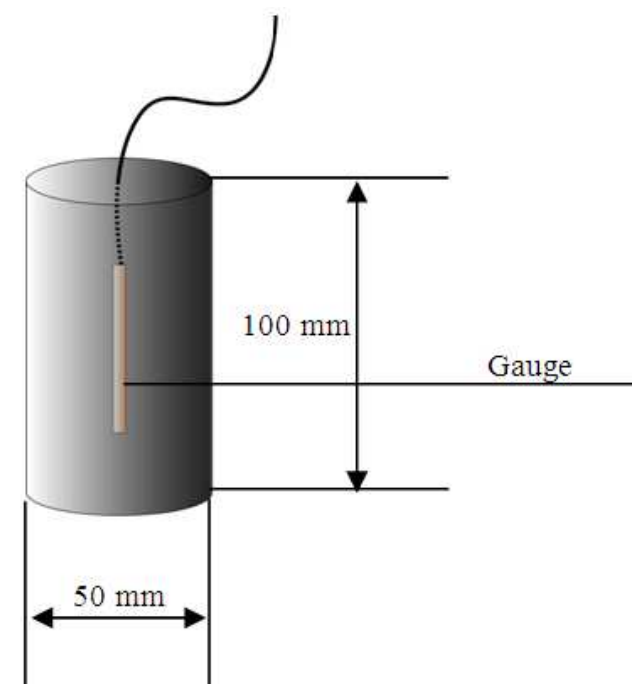

Fig. 3: Dimension of cylindrical specimen

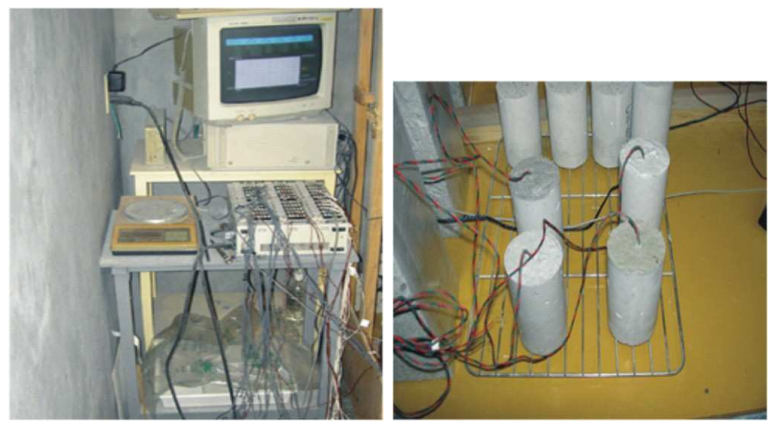

Fig. 4: Instrumentation for free shrinkage test
The outer radius of the mortar ring is $190 \mathrm{~mm}$ therefore its thickness is $40 \mathrm{~mm}$. Then radial drying of ring specimens was conducted in the laboratory atmosphere with $\mathrm{RH}$ of $60 \%$ and at $20^{\circ} \mathrm{C}$. Drying was only allowed from the outer circumferential surface. The large depthto-thickness ratio was chosen to provide uniform drying across the thickness ${ }^{[4]}$.

\section{RESULTS AND DISCUSSION}

The results of free shrinkage testing of premix mortar and light weight hybrid composites are shown in Fig. 5. It can be seen that the drying shrinkage of premix mortar is nearly half the value of light weight hybrid composites. The rate of increase of shrinkage for all materials was high during the first 2 weeks, after that period the rate slowed down and became constant after about 50 days of drying. It is well known that shrinkage of concrete depends on cement, water, sand and paste content ${ }^{[11]}$. The higher the paste content of a concrete, the higher the shrinkage is, since it is the paste property. It is clear that the cement content in light weight hybrid composites is higher than that of premix mortar (compare Table 3 and 4). Therefore, the higher drying shrinkage of light weight hybrid composites than that of premix mortar is due to higher cement content, lower sand content and higher water/cement ratio. Similar results are also reported by Kayali et al. ${ }^{[12]}$ where the drying shrinkage of light weight FRC was found twice as compared to normal weight concrete. The light weight hybrid composites containing FL1 type light weight sand exhibited slightly higher drying shrinkage than the one containing FL0 type light weight sand. This can be attributed to the higher surface area of FL1 type light weight sand than that of FL0 type light weight sand. The increase of drying shrinkage with increase in surface area of aggregates in the concrete was recently observed by Imamoto et al. ${ }^{[13]}$.

The results of restrained shrinkage test (ring test) are shown in Fig. 6 and 7. Figure 6 shows the occurrence of cracks in the ring specimens with progress of time.

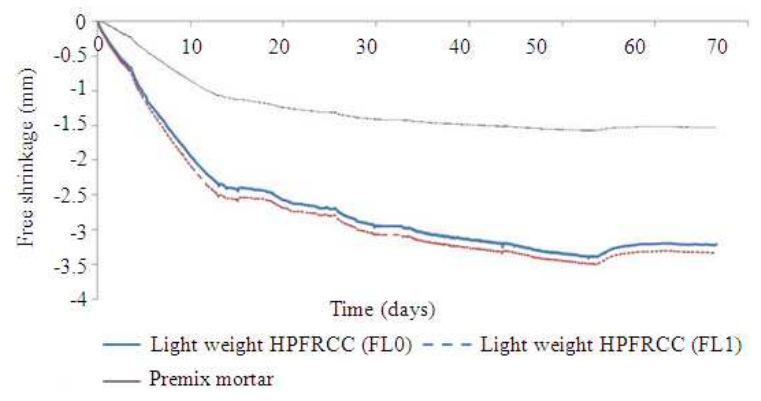

Fig. 5: Free shrinkage of premix mortar and light weight HPFRCC 


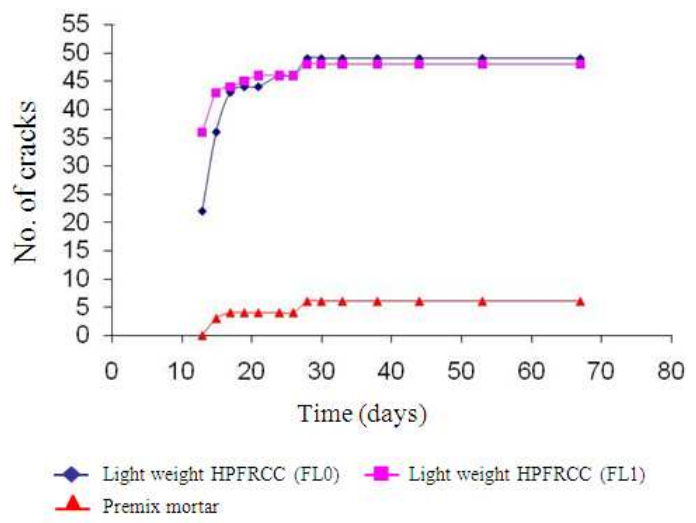

Fig. 6: Number of cracks appeared in premix mortar and light weight HPFRCC ring specimens

It can be seen from the Fig. 6 that after about 2 weeks of drying first crack appeared in the premix mortar specimen whereas at the same time the light weight hybrid HPFRCC specimens containing FL1 and FL0 type light weight sand exhibited about 22 and 35 cracks, respectively. It should be noted that the cracks started to appear in the light weight HPFRCC specimens after about 3 and 4 days of drying. The higher number of cracks observed in the light weight hybrid HPFRCC specimens is due to the strain hardening behavior of this material as compared to its counterpart premix mortar which contained very low amount of fibers. The strain hardening and multiple cracking behavior of light weight HPFRCC materials was observed in the three point bending test as shown in Fig. 1, whereas the premix mortar exhibited quasi brittle behavior. After about four weeks, the formation of cracks in all ring specimens was stabilized and remained constant until the end of the test. At the end of the test, the light weight HPFRCC specimens exhibited about 48 or 49 cracks compared to six cracks in premix mortar specimen.

Throughout the drying shrinkage test, the width of the cracks were monitored and measured. The width of each crack was measured using a microscope at every $48 \mathrm{~h}$ during first few days after cracking and then measured at every four days. The crack width reported here is an average of at least four to six measurements. Figure 7 shows the development of the maximum crack width with progress of time for premix mortar and light weight HPFRCC specimens. It can be seen from the Fig. 7 that the maximum crack width in the premix mortar increases with time meaning that once crack is initiated, it continued to open up with continued drying. This is due to the quasi brittle behavior of this material.

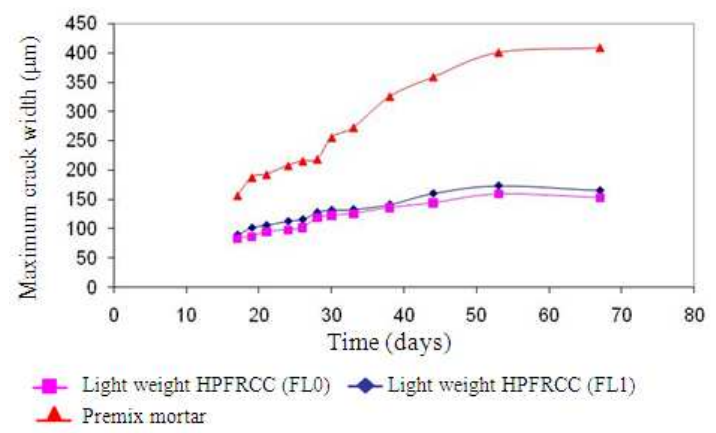

Fig. 7: Maximum crack width in premix mortar and light weight HPFRCC ring specimens

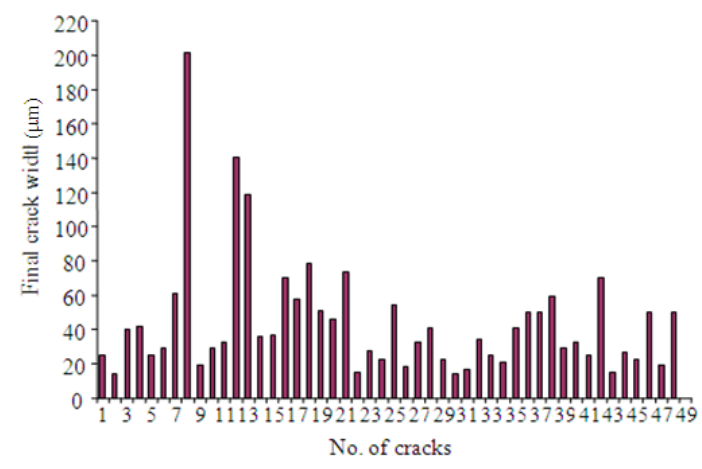

Fig. 8: Final crack width in light weight HPFRCC ring specimen (FL0)

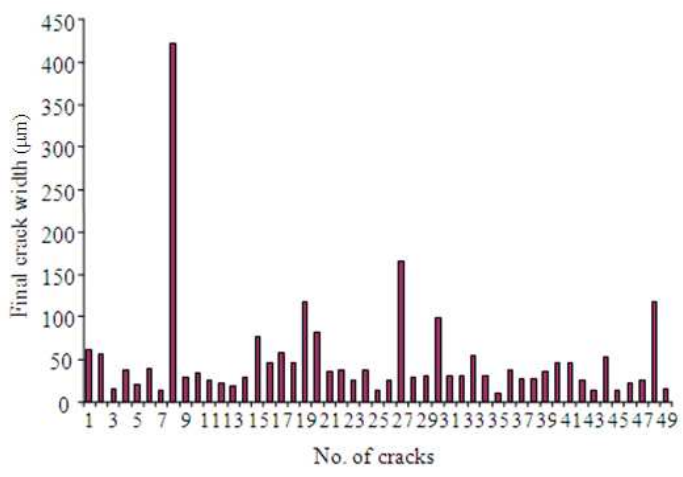

Fig. 9: Final crack width in light weight HPFRCC ring specimen (FL1)

On the other hand, the rate of increase of the maximum crack width in light weight HPFRCC specimens was almost flat. At the end of the test, the width of all cracks of premix mortar and light weight HPFRCC specimens were measured and are plotted in Fig. 8 and 9. Figure 8 shows the measured crack width of light weight HPFRCC material containing FL0 type light weight sand. 


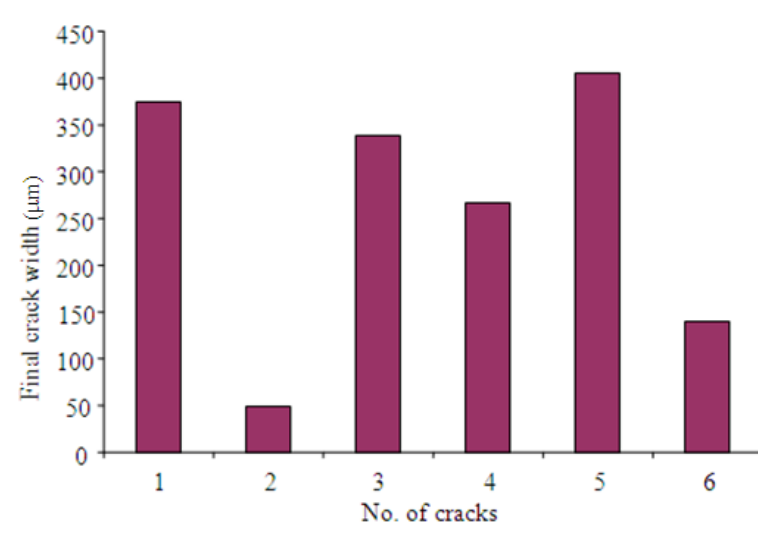

Fig. 10: Final crack width in premix mortar ring specimen

It can be seen from the Fig. 8 that the crack width remain less than $100 \mu \mathrm{m}$ except one or two cracks whose width are about $140-200 \mu \mathrm{m}$ and are believed to be the localized cracks. Similar behavior is also observed in HPFRCC containing light weight sand type FL1 where a localized crack with a maximum crack width of about $430 \mu \mathrm{m}$ is observed (Fig. 9).

The scenario is completely different in case of premix mortar. In Fig. 10 the measured final crack width of premix mortar is shown. As can be seen in the Fig. 10, the number of cracks is limited to only 6 with crack width of most of the cracks ranged between 250 and $400 \mu \mathrm{m}$.

\section{CONCLUSION}

Multiple cracking behavior is observed in the light weight HPFRCC ring specimens in the restrained shrinkage test compared to few cracks (about six) in the premix mortar specimen. The final width of all cracks in the premix mortar specimen is found to be more than $250 \mu \mathrm{m}$ with largest crack width of about $400 \mu \mathrm{m}$. In case of light weight HPFRCC specimens, the width of almost all cracks are less than $100 \mu \mathrm{m}$ except only one crack the width of which is about $400 \mu \mathrm{m}$. The higher numbers of cracks with small crack width observed in light weight HPFRCC materials is due to its strain hardening and high toughness properties which lead to multiple cracking.

\section{ACKNOWLEDGEMENT}

The first reseacher would like to acknowledge the financial assistance in term of post-doctoral fellowship from the Japan Society for the Promotion of Science (JSPS). Authors acknowledge the assistance of Mr. Seisuke Suzuki in the experimental work. Grateful acknowledgement is due to Kuraray Co. Ltd. of Japan for supplying the PVA fibers and Mr. Tsuyoshi Kubota of Saeki Co. Ltd. for supplying other materials.

\section{REFERENCES}

1. Hossain, A.B. and J. Weiss, 2004. Assessing residual stress development and stress relaxation in restrained concrete ring specimens. Cem. Concr. Composit., 26: 531-540. DOI: 10.1016/S09589465(03)00069-

2. Turcry, P., A. Loukili, K. Haidar, G. Pijandier-Cabot and A. Belarbi, 2006. Cracking tendency of selfcompacting concrete subjected to restrained shrinkage: Experimental study and modeling. ASCE J. Mater. Civil Eng., 18: 46-54. DOI: 10.1061/(ASCE)0899-1561(2006)18:1(46))

3. See, H.T., E.K. Attiogbe and M.A. Miltenberger, 2003. Shrinkage cracking characteristics of concrete using ring specimens. Mater. J., 100: 239-245. http://www.concrete.org/PUBS/JOURNALS/OLJD etails.asp?Home=MJ\&ID=12625

4. Grzybowski, M. and S.P. Shah, 1990. Shrinkage cracking of fiber reinforced concrete. Mater. J., 87: $138-148$.

http://www.concrete.org/PUBS/JOURNALS/OLJD etails.asp?Home=MJ\&ID=1951

5. Najm, H. and P. Balaguru, 2002. Effect of large diameter polymeric fibers on shrinkage cracking of cement composites. ACI Mater. J., 99: 345-351. http://dialnet.unirioja.es/servlet/articulo?codigo $=26$ 45521

6. Voigt, T., V.K. Bui and S.P. Shah, 2004. Drying shrinkage of concrete reinforced with fibers and welded wire fabric. Mater. J., 101: 233-241. http://www.concrete.org/PUBS/JOURNALS/OLJD etails.asp?Home $=$ MJ \&ID=13119

7. Filho, R.D.T., K. Ghavami, M.A. Sanjuan and G.L. England, 2005. Free, restrained and drying shrinkage of cement mortar composites reinforced with vegetable fibers. Cement Concrete Composites, 27: 537-546. DOI: 10.1016/j.cemconcomp.2004.09

8. Weimann, M.B. and V.C. Li, 2003. Hygral behavior of Engineered Cementitious Composites (ECC). Int. J. Restorat. Build. Monuments, 9: 513-534. http://ace-

mrl.engin.umich.edu/NewFiles/publications/Weima nn-Li\%20(IRB-2003).pdf

9. Wittmann, F.H., K. Furtwangler and X. Mao, 2005. Optimizing material properties by means of the instrumented ring test. Proceeding of the International Workshop on HPFRCC in Structural Application. Hawaii, USA, pp: 1-8. 
10. Ahmed, S.F.U., H. Mihashi and S. Suzuki, 2006. Mechanical properties of hybrid PVA fiber reinforced cementitious composites under bending. Proceedings of 1st International Structural Specialty Conference, (ISSC'06), CSCE Annual Conference, Calgary, Canada, pp: 1-10.

11. Neville, A.M., 1997. Properties of Concrete. 4th Edn., Longman Publishing Group, ISBN: 100582230705 .
12. Kayali, O., M.N. Haque and B. Zhu, 1999. Drying shrinkage of fiber reinforced lightweight aggregate concrete containing fly ash. Cem. Concr. Res., 29: $\quad 1835-1840 . \quad$ DOI: $10.1016 / \mathrm{S} 0008-$ 8846(99)00179-9

13. Imamoto, K. and M. Arai, 2008. Specific surface area of aggregate and its relation to concrete drying shrinkage. J. Mater. Struct., 41: 323-333. DOI: 10.1617/s11527-007-9245-x 